"This is the peer reviewed version of the following article: Angew. Chem. Int. Ed. 2017, 56 (23), 6558-6562

, which has been published in final form at http://onlinelibrary.wiley.com/doi/10.1002/anie.201702857/abstractThis article may be used for non-commercial purposes in accordance with Wiley Terms and Conditions for Self-Archiving."

\title{
Switchable Site-Selective Catalytic Carboxylation of Allylic Alcohols with $\mathrm{CO}_{2}$
}

\begin{abstract}
Manuel van Gemmeren, ${ }^{\dagger}$ Marino Börjesson, ${ }^{\dagger}$ Andre and Ruben Martin*

Abstract: A switchable site-selective catalytic carboxylation of allylic alcohols has been developed in which $\mathrm{CO}_{2}$ is used with dual roles, both facilitating $\mathrm{C}-\mathrm{OH}$ cleavage and as $\mathrm{C} 1$ source. This protocol is characterized by its mild conditions, absence of stoichiometric organometallic reagents, broad scope and exquisite regiodivergency that can be modulated by the ligand employed.
\end{abstract}

Metal-catalyzed cross-coupling reactions of $\mathrm{C}-\mathrm{O}$ electrophiles have recently gained considerable momentum due to the ready availability of alcohols and the design of orthogonal techniques in the presence of organic halides. ${ }^{[1]}$ Unlike common $\mathrm{C}-\mathrm{C}$ bondformations with activated organic sulfonates, esters, and ethers, the use of simple alcohols as counterparts, arguably the most accessible and simplest $\mathrm{C}-\mathrm{O}$ derivative, has received much less attention. Despite advances realized in nucleophilic/electrophilic regimes (Scheme 1, bottom left), ${ }^{[2],[3]}$ alcohols should ideally be utilized within the realm of cross-electrophile couplings ${ }^{[4]}$ thus avoiding the need for highly reactive nucleophilic entities. However, the remarkable activation barrier required for $\mathrm{C}-\mathrm{OH}$ scission and the high polarizability of the $\mathrm{O}-\mathrm{H}$ bond $^{[5]}$ left a reasonable doubt that such a counterintuitive scenario could ever be implemented (Scheme 1, bottom right). If successful, however, the realization of such a technique could unravel the inherent potential of simple alcohols in cross-electrophile events, constituting a unique opportunity to provide new tactics for building up complexity from simple precursors.

[] M. van Gemmeren, M. Börjesson, A. Tortajada, S. -Z. Sun, K. Okura, Prof. R. Martin

Institute of Chemical Research of Catalonia (ICIQ)

The Barcelona Institute of Science and Technology

Av. Països Catalans 16, 43007 Tarragona (Spain)

E-mail: rmartinromo@iciq.es

Prof. R. Martin

ICREA, Passeig Lluïs Companys, 23, 08010 Barcelona Spain

['] These authors contributed equally to this work

Supporting information for this article is given via a link at the end of the document.((Please delete this text if not appropriate))
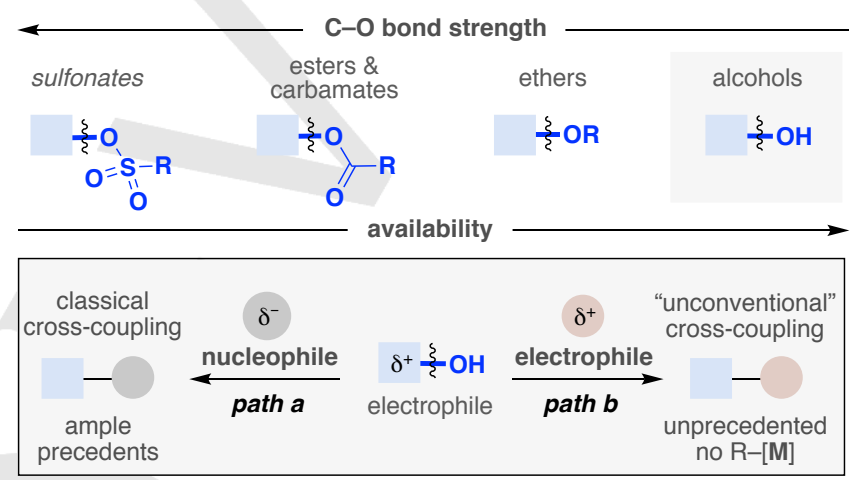

Scheme 1. Catalytic C-C Bond-Formation with Alcohols as Coupling Partners

Prompted by the seminal stoichiometric work of Osakada, ${ }^{[6]}$ $\mathrm{we}^{[7]}$ and others ${ }^{[8]}$ launched a program aimed at unraveling the potential of nickel-catalyzed reductive carboxylation of organic (pseudo)halides with carbon dioxide $\left(\mathrm{CO}_{2}\right)$. At present, these endeavors unfortunately remain limited to organic halides or particularly activated $\mathrm{C}-\mathrm{O}$ electrophiles. ${ }^{[9]}$ As $\mathrm{C}-\mathrm{O}$ electrophiles ultimately derive from the corresponding alcohol, we recently questioned whether we could establish a design principle for promoting a more atom- and step-economical technique via direct $\mathrm{Ni}$-catalyzed carboxylation of simple unprotected alcohols in the absence of stoichiometric or air-sensitive organometallic reagents. ${ }^{[10]}$ To such end, we hypothesized that $\mathrm{CO}_{2}$ could be used with dual roles, both as $\mathrm{C} 1$ source and as an activating group for $\mathrm{C}-\mathrm{O}$ bond-cleavage (Scheme 2). Our hypothesis is driven by the known ability of $\mathrm{CO}_{2}$ to react reversibly with alcohols en route to carbonic acids $\mathrm{I}^{[11]}$ thus lowering the activation energy for promoting $\mathrm{C}-\mathrm{O}$ scission while accelerating the rate of oxidative addition to $\mathrm{Ni}(0) \mathrm{L}_{\mathrm{n}}$ (III vs II) prior $\mathrm{CO}_{2}$ insertion. ${ }^{[12]}$ Herein, we describe our results towards this goal by designing a mild, and user-friendly Ni-catalyzed carboxylation of allylic alcohols under atmospheric pressure of $\mathrm{CO}_{2}$. We demonstrate that the site-selectivity at the allyl terminus can be discriminated and modulated at will by the ligand employed, leading to either linear or $\alpha$-branched carboxylic acids. ${ }^{[13]}$ 
WILEY-VCH

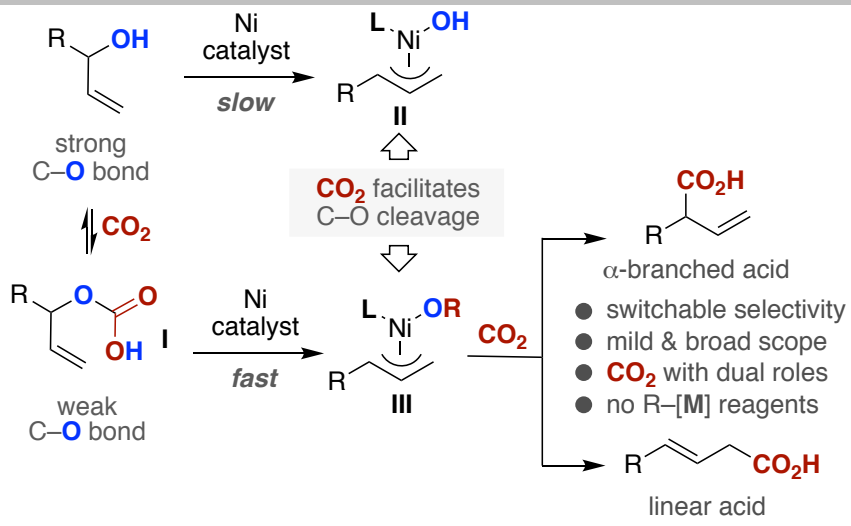

Scheme 2. Design Principle for a Carboxylation of Allylic Alcohols with $\mathrm{CO}_{2}$

Our study began by evaluating the carboxylation of 1 at atmospheric pressure of $\mathrm{CO}_{2}$. Interestingly, neither $\mathbf{2 a}$ nor $\mathbf{2 b}$ were observed under conditions previously developed for other carboxylation events. ${ }^{[7,8]}$ After some experimentation, a combination of $\mathrm{NiBr}_{2} \cdot$ glyme, commercially available L3, Zn, $\mathrm{MgCl}_{2}$ and DMF at $40{ }^{\circ} \mathrm{C}$ afforded $2 \mathrm{a}$ in $70 \%$ isolated yield with exquisite site-selectivity $(\mathbf{2 a : 2 b}=99: 1) \cdot{ }^{[14]}$ Inferior results were consistently observed with $\mathrm{Ni}$ sources, additives and solvents other than $\mathrm{NiBr}_{2}$.glyme, $\mathrm{MgCl}_{2}$, and DMF (entries 2 and 3). Similarly, lower yields were found when $\mathrm{MgBr}_{2}$ or ammonium salts were used in lieu of $\mathrm{MgCl}_{2}$ (entries 4 and 5). ${ }^{[15]}$ Traces of $\mathbf{2 a}$ if any, were observed when using $\mathrm{Mn}$ or silanes as reducing agents (entry 6). The former finding is particularly noteworthy given the notorious success of $\mathrm{Mn}$ as reductant in crosselectrophile couplings, ${ }^{[4]}$ including carboxylation protocols. ${ }^{[7,8]}$ As expected, the nature of the ligand exerted a profound influence in both reactivity and site-selectivity. While excellent regioselectivities towards $\mathbf{2 a}$ were found with 2,2'-bipyridines and 1,10-phenanthrolines possessing substituents adjacent to the nitrogen atom, better yields were found for the latter (entries 7-11). At present, we hypothesize that these results account for the higher rigidity of 1,10-phenanthrolines, likely increasing the stability of the putative reaction intermediates within the catalytic cycle. Interestingly, bench-stable C6-substituted terpyridines L7L8, resulted in a selectivity switch en route to $\mathbf{2 b}$ under identical reaction conditions to that shown for L3, albeit in lower yields (entry 12 and 13 ). ${ }^{[16]}$ It is worth noting that related quaterpyridine analogue such as $\mathbf{L} \mathbf{6}$ failed to provide $\mathbf{2 b} .^{[17]}$ These results tacitly suggest that the coordination geometry of the ligand dictates the selectivity pattern, with tridentate ligands being particularly suited for $\mathbf{2 b}$. Careful fine-tuning of the reaction conditions afforded $\mathbf{2} \mathbf{b}$ in $81 \%$ isolated yield with an excellent 3:97 2a:2b ratio when using $\mathrm{Ni}(\mathrm{COD})_{2}$ as catalyst in DMA at rt, and employing both $\mathrm{CaCl}_{2}$ and $\mathrm{NEt}_{3}$ as additives (entry 14). ${ }^{[18]}$ As anticipated, rigorous control experiments revealed that all of the reaction parameters were critical for success. ${ }^{[14]}$

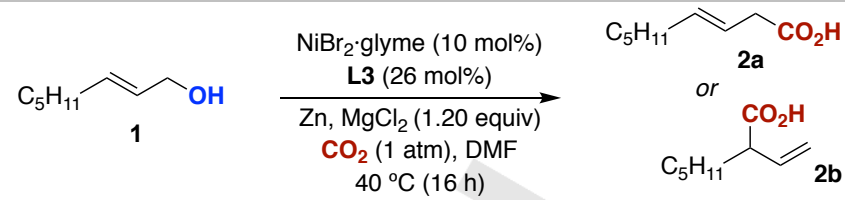

entry Deviation from standard conditions ${ }^{[a]} \quad$ yield $2 a+2 b(\%)^{[b]} \quad 2 a: 2 b^{[b]}$

1 none $\quad 70,[c] 26^{[d]} \quad 99: 1$

2 Using $\mathrm{NiCl}_{2} \cdot$ glyme $\left(\mathrm{Ni}(\mathrm{COD})_{2}\right) \quad 58(69) \quad 99: 1$

$3 \mathrm{DMA}(\mathrm{NMP})$ as solvent $\quad 51(52) \quad 99: 1$

$4 \mathrm{MgBr}_{2}$ instead of $\mathrm{MgCl}_{2} \quad 52 \quad 99: 1$

$5 n \mathrm{Bu}_{4} \mathrm{NBr}\left(n \mathrm{Bu}_{4} \mathrm{NOAc}\right)$ instead of $\mathrm{MgCl}_{2} \quad 0(48) \quad 99: 1$

$6 \mathrm{Mn}\left(\mathrm{Et}_{3} \mathrm{SiH}\right)$ instead of $\mathrm{Zn} \quad 3(0) \quad 99: 1$

7 L1 instead of L3 $\quad 3 \quad 66: 34$

$8 \quad$ L2 instead of L3 $\quad 42 \quad 99: 1$

9 L4 instead of L3 $\quad 54 \quad 99: 1$

10 L5 instead of L3 $23 \quad 99: 1$

11 L6 instead of L3 -

$12 \quad$ L7 instead of L3 $\quad 18 \quad 23: 77$

13 L8 instead of L3 $\quad 30 \quad 4: 96$

$14 \quad \mathbf{L 8}$ instead of $\mathbf{L 3}$, with $\mathrm{CaCl}_{2}$ and $\mathrm{NEt}_{3} \quad 55, \mathbf{8 1}^{[\mathrm{c}, \mathrm{e}]} \quad \mathbf{3 : 9 7}$<smiles>[R]c1cc([R])nc(-c2cccc(-c3cc([R7])cc([R])n3)n2)c1</smiles>

$\mathrm{R}^{1}=\mathrm{H} ; \mathrm{R}^{2}=\mathrm{Ph}, \mathrm{L} 1 \quad \mathrm{R}=n-\mathrm{Bu}, \mathrm{L} 5 \quad \mathrm{R}^{1}=\mathrm{Me} ; \mathrm{R}^{2}=\mathrm{H}, \mathrm{L} 7$

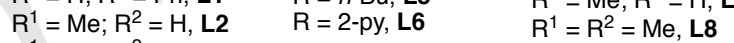

$\mathrm{R}^{1}=\mathrm{Me} ; \mathrm{R}^{2}=\mathrm{Ph}, \mathrm{L} 3$

$\mathrm{R}^{1}=\mathrm{n}-\mathrm{Bu} ; \mathrm{R}^{2}=\mathrm{Ph}, \mathrm{L} 4$

Scheme 3. Optimization of the Reaction Conditions. 1 (0.20 mmol), $\mathrm{NiBr}_{2}$-glyme (10 mol\%), L3 (26 mol\%), Zn (4 equiv), $\mathrm{MgCl}_{2}$ (1.20 equiv), DMF $(0.10 \mathrm{M}), \mathrm{CO}_{2}(1 \mathrm{~atm})$ at $40^{\circ} \mathrm{C}$ for $16 \mathrm{~h}$ (yields in parentheses refer to yields of the reagents used in parentheses). ${ }^{[b]} \mathrm{GC}$ yields using anisole as internal standard. ${ }^{[c]}$ Isolated yield. ${ }^{[\mathrm{d}]} \mathrm{No} \mathrm{MgCl}_{2} .{ }^{[\mathrm{e}]} \mathrm{Ni}(\mathrm{COD}) 2$ (10 mol\%), L8 (10 mol\%), $\mathrm{CaCl}_{2}$ (4 equiv), $\mathrm{NEt}_{3}$ (3 equiv), $\mathrm{Zn}$ (1.50 equiv), DMA $(0.20 \mathrm{M})$ at rt. 


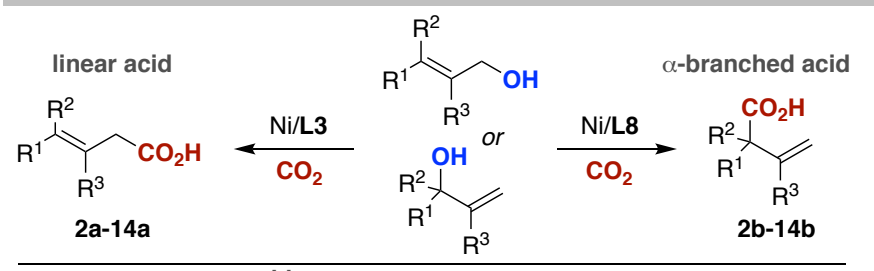

conditions A (Ni/L3) ${ }^{[a]}$

$$
\text { }
$$<smiles>O=C(O)CC=CC1CCCCC1</smiles><smiles>C=C(CC(=O)O)Cc1ccccc1</smiles>

$\mathrm{R}=\mathrm{OMe}, \mathbf{8 a}, 63 \%[\mathrm{~d}]$ $\mathrm{R}=$ OPiv, $9 \mathrm{a}, 71 \%$ [d] $\mathrm{Cl}$<smiles>O=C(O)C/C=C\CCc1ccccc1Cl</smiles>

13a, $65 \%$ [d]<smiles>CC(=CCCc1ccccc1)CC(=O)O</smiles>

6a, $66 \%$<smiles>CC(/C=C/CC(=O)O)Cc1ccc2c(c1)OCO2</smiles>
$10 a, 60 \%[d]$<smiles>CC(=CCC(=O)O)CCc1ccccc1</smiles>

14a, $66 \%[\mathrm{e}]$

conditions B (Ni/L8) ${ }^{[i]}$<smiles>C=CC(CCCCC)C(=O)O</smiles>

2b, $81 \%$, ${ }^{[b]} 81 \%$ [c]<smiles>C=CC(CCCc1ccccc1)C(=O)O</smiles>

5b, $76 \%$<smiles>[R]c1ccc(CCC(C=C)C(=O)O)cc1</smiles>

$\mathrm{R}=\mathrm{OMe}, \mathbf{8 b}, 64 \%$ $\mathrm{R}=$ OPiv, $9 \mathbf{b}, 66 \%$<smiles>C=CC(CCc1ccccc1Cl)C(=O)O</smiles>

13b, $65 \%$<smiles>C=CC(C(=O)O)C1CCCCC1</smiles>

3b, $67 \%[\mathrm{j]}$<smiles>C=C(C)C(CCc1ccccc1)C(=O)O</smiles>

$6 b, 82 \%$<smiles>C=C[C@H](Cc1ccc2c(c1)OCO2)[C@@H](C)C(=O)O</smiles><smiles>C=C(CC(=O)O)Cc1ccccc1</smiles>

4a, $71 \%$<smiles>C=CC(CCc1cccc2ccccc12)C(=O)O</smiles>

7b, $70 \%$
$\mathrm{R}=\mathrm{CF}_{3}, 11 \mathrm{a}, 64 \%[\mathrm{~d}]$<smiles>CC(C)=CCCC(C)=CCC(=O)O</smiles>

$15 a, 76 \%,{ }^{[\mathrm{f}]} 60 \%,{ }^{[\mathrm{g}]} 68 \%{ }^{[\mathrm{h}]}$ $\mathrm{R}=\mathrm{CO}_{2} \mathrm{Et}, \mathbf{1 2 a}, 57 \%[\mathrm{~d}]$

$\mathrm{CO}_{2}$ by using a Ni/L3 or Ni/L8 couple (Scheme 4). In all cases analyzed, an exquisite site-selectivity was observed regardless of whether linear or $\alpha$-branched allylic alcohols were utilized, thus indicating that a substrate-controlled site-selectivity does not come into play. Notably, the substitution pattern on the allyl terminus was largely inconsequential for both reactivity and siteselectivity, obtaining predominantly the corresponding linear or $\alpha$-branched carboxylic acids. The presence of esters $(12 \mathbf{a}, 12 \mathbf{b})$, acetals $(10 \mathbf{a}, \mathbf{1 0 b})$, alkenes $(\mathbf{1 5 a}, \mathbf{1 5 b})$ or even aryl chlorides (13a, 13b) do not interfere, providing ample room for further functionalization. Likewise, the presence of $\mathrm{C}-\mathrm{O}$ electrophilic sites susceptible to $\mathrm{Ni}$-catalyzed cross-coupling reactions such as aryl methyl ethers $(\mathbf{8} \mathbf{a}, \mathbf{8 b})$ or aryl pivalates $(\mathbf{9 a}, \mathbf{9 b})$ did not compete with the efficacy of the carboxylation event. Particularly noteworthy was the ability to access quaternary centers (14b and 15b), as cross-electrophile endeavors have found little echo with tertiary alkyl electrophiles. ${ }^{[19]}$ While a Ni/L3 regime provided predominantly $(E)$-configured isomers, we observed an intriguing dichotomy exerted by the geometry of the starting precursor. Specifically, naturally-occurring geraniol gave rise to 15 a with a higher $E: Z$ ratio than structurally isomeric nerol and linalool. While tentative, a subtle $\eta^{1}$ to $\eta^{3}$ hapticity of the intermediate allyl-Ni complex or the known ability of tethered alkenes on the side-chain to act as intramolecular directing groups might account for these results. ${ }^{[20]}$ In contrast, $15 \mathbf{b}$ was exclusively obtained from either geraniol, nerol or linalool with a Ni/L8 couple. It is worth mentioning that substituents in the $\alpha$-position of the allyl motif did not erode the site-selectivity, giving rise to $10 \mathrm{a}$ and $10 \mathrm{~b}$ in good yields, respectively. The synthetic applicability of our Ni-catalyzed carboxylation in the context of natural product synthesis is further illustrated in Scheme 5 . Specifically, a simple three-step sequence consisting of a direct carboxylation of 1 a followed by esterification with $\mathrm{TMSCHN}_{2}$ and Sharpless asymmetric dihydroxylation afforded 16 in good overall yield, constituting a formal total synthesis of $(+)$-transcognac lactone ${ }^{[21]} 17$ and other related natural products. ${ }^{[22]}$ Taken together, the results compiled in both Schemes 4 and 5 shows the prospective potential of our methodology.
$10 \mathrm{~b}, 80 \%{ }^{[\mathrm{k}]}$

$\mathrm{R}=\mathrm{CF}_{3}, \mathbf{1 1 b}, 73 \%$ $\mathrm{R}=\mathrm{CO}_{2} \mathrm{Et}, \mathbf{1 2 b}, 73 \%$

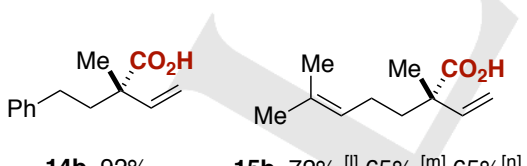

$14 b, 92 \%$ 15b, $72 \%,{ }^{[l]} 65 \%,{ }^{[\mathrm{m}]} 65 \%{ }^{[\mathrm{n}]}$
Scheme 4. Scope of the Regiodivergent Carboxylation of Allylic Alcohols with $\mathrm{CO}_{2}$. ${ }^{\text {a] }}$ Conditions $\mathrm{A}$ : as scheme 3 , entry 1 , at $0.25 \mathrm{mmol}$ scale; Yields of isolated products, average of at least two independent runs. 2a-15a were all obtained in 99:1 (linear:branched) ratio. 2a-13a were obtained in $292: 8 E: Z$ ratio. ${ }^{[b]}$ from linear alcohol. ${ }^{[c]}$ from $\alpha$-branched alcohol. ${ }^{[d]} Z n$ (2.50 equiv) in $\operatorname{DMF}(0.70 \mathrm{M}) .{ }^{[\mathrm{e}]} E: Z=45: 55 .{ }^{\text {[f] }}$ from geraniol, $E: Z=94: 6 .{ }^{\text {[g] }}$ from nerol, $E: Z=$ 16:84. ${ }^{[\mathrm{h}]}$ from linalool, $E: Z=42: 58$. ${ }^{[i]}$ Conditions $B$ : as scheme 3 , entry 14 , at $0.25 \mathrm{mmol}$ scale; Yields of isolated products, average of at least two independent runs. With the exception of $3 \mathbf{b}$ and $10 \mathrm{~b}$, all products were obtained in $\geq 92: 8$ (branched: linear) ratio. ${ }^{[\mathrm{j}]} 82: 18$ (3b:3a). ${ }^{[\mathrm{k}]}$ 85:15 (10b:10a) and 1:1 diastereomeric ratio. ${ }^{[1]}$ from geraniol. ${ }^{[\mathrm{m}]}$ from nerol. ${ }^{\left[{ }^{[n]}\right.}$ from linalool.

With a reliable access to either $\mathbf{2 a}$ or $\mathbf{2} \mathbf{b}$, we next turned our attention to evaluate the generality of our Ni-catalyzed switchable site-selective carboxylation of allylic alcohols with

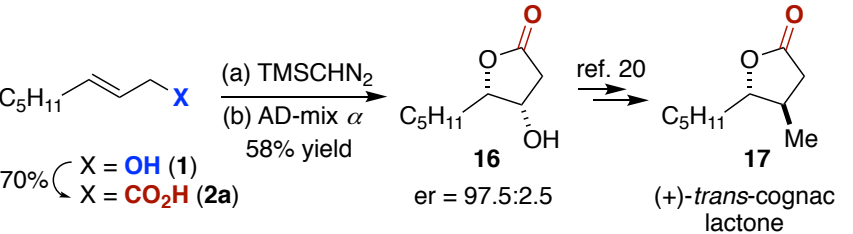

Scheme 5. Formal Total Synthesis of (+)-trans-Cognac Lactone.

While an unambiguous understanding on how these reactions work at the molecular level should await further investigations, we turned our attention to gather empirical evidence about the intriguing role of the ligand by studying the reactivity of the putative $\mathrm{Ni}(0) L_{n}$ species (Scheme 6). Particularly noteworthy was the absence of reactivity when simply exposing 18 to stoichiometric amounts of either $\mathrm{Ni}(0)(\mathbf{L} 3)_{2}{ }^{[23]}$ or $\mathrm{Ni}(\mathrm{COD})_{2} / \mathbf{L} 8^{[24]}$ in the absence of $\mathrm{CO}_{2}$, thus reinforcing the notion that a direct oxidative addition of an allylic alcohol to $\mathrm{Ni}(0) L_{n}$ does not come into play. ${ }^{[25]}$ More importantly, while a $\mathrm{Ni}(0)(\mathbf{L} 3)_{2}$ regime required the presence of $\mathrm{Zn}$ en route to $19 \mathrm{a},{ }^{[23]}$ the corresponding $\mathrm{Ni}(\mathrm{COD})_{2} / \mathbf{L} 8$ couple cleanly produced $19 \mathrm{~b}$ in the absence of reductant, thus evidencing the unique role exerted by the ligand 
backbone. ${ }^{[26]}$ Although speculative, these results might suggest the intermediacy of $\eta^{1}-\mathrm{Ni}(\mathrm{I})$ intermediates with bidentate and rigid L3, in which $\mathrm{CO}_{2}$ insertion takes place at the $\alpha$-carbon $(19 a),{ }^{[27-30]}$ whereas the presence of tridentate $\mathbf{L} 8$ might result in $\eta^{1}-\mathrm{Ni}(\mathrm{II})$ intermediates with $\mathrm{C}-\mathrm{C}$ bond-formation occurring at the $\gamma$-carbon (19b). ${ }^{[30-32]}$

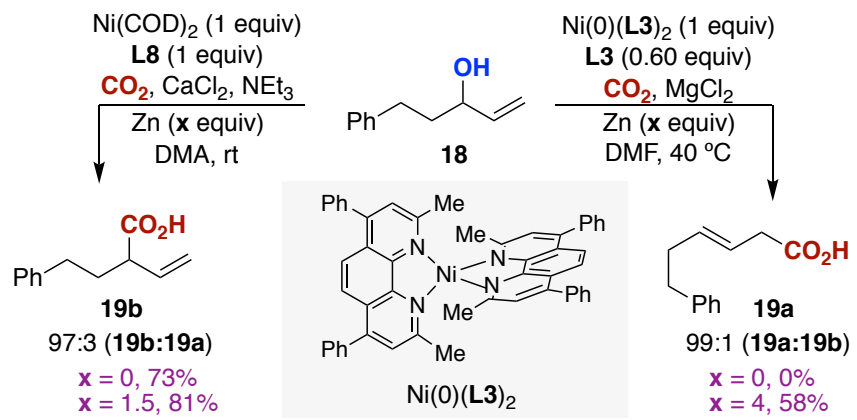

Scheme 6. Preliminary Mechanistic Experiments

In summary, we have documented a Ni-catalyzed switchable site-selective reductive carboxylation of allylic alcohols, in which regiodivergency is exclusively dictated by the geometry of the ligand backbone. The salient features of this user-friendly method are the broad scope, mild conditions, exquisite siteselectivity profile and the ability of $\mathrm{CO}_{2}$ to act with dual roles, both as $\mathrm{C} 1$ source and as a mediator for facilitating $\mathrm{C}-\mathrm{O}$ scission. We anticipate that this method will foster systematic investigations for a more prolific use of simple alcohols in crosselectrophile reactions. Further work along these lines is being conducted in our laboratories.

\section{Acknowledgements}

We thank ICIQ, the European Research Council (ERC-277883), MINECO (Severo Ochoa Excellence Accreditation 2014-2018, SEV-2013-0319 \& CTQ2015-65496-R, MINECO-FEDER-UE) and Cellex Foundation for support. Johnson Matthey, Umicore and Nippon Chemical Industrial are acknowledged for a gift of metal \& ligand sources. MvG, M.B and A.T thank Alexander von Humboldt-Foundation and MINECO for a postdoctoral and predoctoral scholarships.

Keywords: cross-coupling $\cdot$ nickel $\cdot$ carbon dioxide $\cdot$ C-O cleavage

[1] (a) C. Zarate, M. van Gemmeren, R. J. Somerville, R. Martin, Adv. Organomet.Chem. 2016, 66,143; (b) M. Tobisu, N. Chatani, Acc. Chem. Res. 2015, 48,1717; (c) E. J. Tollefson, L. E. Hanna, E. R. Jarvo, Acc. Chem. Res. 2015, 48,2344; (d) B. Su, Z. -C. Cao, Z. -J. Shi, Acc.Chem. Res. 2015, 48, 886; (e) J. Cornella, C. Zarate, R. Martin, Chem. Soc.Rev. 2014, 43, 8081; (f) J. Yamaguchi, K. Muto, K. Itami, Eur.J.Org. Chem. 2013,19 (g) B. M. Rosen, K. W. Quasdorf, D.A. Wilson, N. Zhang, A. -M. Resmerita, N. K. Garg, V. Percec, Chem. Rev. 2011, 111,1346

[2] While activation of allylic alcohols with $\mathrm{CO}_{2}$ has been explored using $\mathrm{Pd}$, Ir, Rh as catalysts, analogous activation technologies using nickel catalysts are rare. For excellent reviews dealing with cross-coupling reactions of allylic alcohols with nucleophilic entities via the intermediacy of $\pi$-allylic species: (a) N. A. Butt, W. Zhang, Chem. Soc.
Rev. 2015, 44, 7929; (b) B. Sundararaju, M. Achard, C. Bruneau, Chem. Soc. Rev. 2012, 41, 4467; (c) Y. Tamaru, Eur. J. Org. Chem. 2005, 2647

[3] For selected cross-coupling reactions of alcohols with nucleophilic species, see: (a) Y. Kita, R. D. Kavthe, H. Oda, K. Mashima, Angew. Chem., Int. Ed. 2016, 55, 1098; Angew.Chem. 2016, 128,1110; (b) Z. C. Cao, D. -G. Yu, R. -Y. Zhu, J. -B. Wei, Z. -J. Shi, Chem. Commun. 2015, 51, 2683; (c) X. Huo, G. Yang, D. Liu, Y. Liu, I. D. Gridnev, W. Zhang, Angew. Chem., Int. Ed. 2014, 53, 6776; Angew. Chem. 2014 126, 6894; (d) J. Y. Hamilton, S. Krautwald, D. Sarlah, M. Schafroth, E. M. Carreira, Science 2013, 340, 1065; (e) J. Y. Hamilton, D. Sarlah, E. M. Carreira, J. Am. Chem. Soc., 2013, 135, 994; (f) G. -X. Jiang, B. List, Angew. Chem., Int. Ed. 2011, 50, 9471; Angew. Chem. 2011, 123, 9643; (g) D. -G. Yu, B. -J, Li, S. -F. Zheng, B. -T. Guan, B. -Q. Wang, Z. -J. Shi, Angew. Chem. Int. Ed. 2010, 49, 4566; Angew. Chem. 2010 122, 4670; (h) T. Yamamoto, J. Ishizu, A. Yamamoto, J. Am. Chem. Soc., 1981, 103, 6863, and references therein.

[4] For selected reviews: a) J. Gu, X.Wang, W. Xue, H. Gong, Org. Chem. Front. 2015, 3, 1411-1421; b) J. D. Weix, Acc. Chem. Res. 2015, 48 1767-1775; c) T. Moragas, A. Correa, R. Martin, Chem. Eur. J. 2014, 20, 8242-8258; d) C. E. I. Knappke, S. Grupe, D. Gärtner, M. Corpet, C. Gosmini, A. Jacobi von Wangelin, Chem. Eur. J. 2014, 20, 6828-6842

[5] S. J. Blanksby, G. B. Ellsion, Acc. Chem. Res. 2003, 36, 255

[6] K. Osakada, R. Sato, T. Yamamoto, Organometallics 1994, 13, 4645

[7] For selected references: (a) T. Moragas, M. Gaydou, R. Martin, Angew. Chem., Int. Ed. 2016, 55, 5053; Angew. Chem. 2016, 128, 5137; (b) X. Wang, M. Nakajima, R. Martin, J. Am. Chem. Soc. 2015, 137, 8924; (c) X. Wang, Y. Liu, R. Martin, J. Am. Chem. Soc. 2015, 137, 6476; (d) Y. Liu, J. Cornella, Martin, R. J. Am. Chem. Soc. 2014, 136, 11212; (e) A. Correa, T. León, R. Martin, J. Am. Chem. Soc. 2014, 136, 1062.

[8] For selected references: (a) F. Rebih, M. Andreini, A. Moncomble, A. Harrison-Marchand, J. Maddaluno, M. Durandetti, Chem. - Eur. J. 2016 , 22, 3758; (b) K. Nogi, T. Fujihara, J. Terao, Y. Tsuji, J. Org. Chem. 2015, 80, 11618; (c) K. Nogi, T. Fujihara, J. Terao, Y. Tsuji, Chem. Commun. 2014, 50, 13052; (d) H. Tran-Vu, O. Daugulis, ACS Catal. 2013, 3, 2417; (e) T. Fujihara, K. Nogi, T. Xu, J. Terao, Y. Tsuji, J. Am. Chem. Soc. 2012,134, 9106.

[9] M. Börjesson, T. Moragas, D. Gallego, R. Martin, ACS Catal. 2016, 6, 6739.

[10] For an elegant regioselective (not regiodivergent) carboxylation with stoichiometric, air-sensitive and pyrophoric $\mathrm{Et}_{2} \mathrm{Zn}$ as reducing agent: $\mathrm{T}$. Mita, Y. Higuchi, Y. Sato, Chem. - Eur. J. 2015, 21, 16391

[11] (a) R. R. Weikel, J. P.; Hallett, C. L. Liotta, C. A. Eckert, Ind. Eng. Chem. Res. 2007, 46, 5252; (b) M. Sakamoto, I. Shimizu, A. Yamamoto, Bull. Chem. Soc. Jpn. 1996, 69, 1065;

[12] For an elegant Pd-catalyzed cross-coupling reaction with nucleophilic entities promoted by $\mathrm{CO}_{2}$, see: S. B. Lang, T. M. Locascio, J. A. Tunge, Org. Lett. 2014, 16, 4308.

[13] For a selection of elegant linear-selective reductive-couplings of other allyl electrophiles, see: (a) L. L. Anka-Lufford, M.R. Prinsell, D.J. Weix, J. Org. Chem. 2012, 77, 9989; (b) X. Qian, A. Auffrant, A. Felouat C. Gosmini, Angew. Chem. Int. Ed. 2011, 50, 10402; Angew. Chem. 2011, 123, 10586; (c) Y. Dai, F. Wu, Z. Zang, H. You, H. Gong, Chem. Eur. J. 2012, 18, 808.

[14] See Supporting information for details. The mass balance accounts for unreacted starting material and reduction events.

[15] For the beneficial role of $\mathrm{MgCl}_{2}$ in cross-electrophile events, see: (a) C. Zhao, X. Jia, X. Wang, H. Gong J. Am. Chem. Soc. 2014, 136, 17645; (b) T. Leon, A. Correa, R. Martin, J. Am. Chem. Soc. 2013, 135, 1221; c) F. Wu, W. Lu, Q. Qian, Q. Ren, H. Gong, Org. Lett. 2012, 14, 3044.

[16] While $\mathbf{L} \mathbf{7}$ is commercially available, $\mathbf{L} \mathbf{8}$ could easily be prepared from simple precursors. See ref. 13.

[17] These results are in sharp contrast with the ability of quaterpyridine ligands to promote carboxylation processes of allyl ester derivatives: $T$. Moragas, J. Cornella, R. Martin, J. Am. Chem. Soc. 2014, 136, 17702.

[18] Although tentative, Lewis acids $\left(\mathrm{MgCl}_{2}\right.$ or $\left.\mathrm{CaCl}_{2}\right)$ might react with the corresponding carbonic acid generated in situ upon exposure of 1 with $\mathrm{CO}_{2}$, thus accelerating $\mathrm{C}-\mathrm{O}$ bond-cleavage. Importantly, an identical regioselectivity was found regardless of whether $\mathrm{CaCl}_{2}$ or $\mathrm{MgCl}_{2}$ were utilized, thus reinforcing the notion that the site-selectivity was dictated by the ligand employed. As for the role of $\mathrm{NEt}_{3}$, it could potentially act 
as a proton scavenger to prevent the formation of reduced products. See ref. 13.

[19] (a) X. Wang, S. Wang, W. Xue, H. Gong, J. Am. Chem. Soc. 2015, 137, 11562; (b) C. Zhao, X. Jia, X. Wang, H. Gong, J. Am. Chem. Soc. 2014, 136, 17645; (c) M. Börjesson, T. Moragas, R. Martin, J. Am. Chem. Soc. 2016, 138, 7504; (d) Ref. 16

[20] K. M. Miller, T. F. Jamison, J. Am. Chem. Soc. 2004, 126, 15342

[21] H. Takahata, Y. uchida, T. Momose, J. Org. Chem. 1995, 60, 5628

[22] (a) T. Kapferer, R. Brückner, A. Herzig, W. A. König, Chem. Eur. J. 2005, 11, 2154; (b) C. García, M. Soler, V. S. Martín, Tetrahedron Lett. 2000, 41, 4127.

[23] For the synthesis of $\mathrm{Ni}(0)(\mathbf{L} 3)_{2}$ see ref. $7 \mathrm{c}$. When $\mathrm{Ni}(0)(\mathbf{L} 3)_{2}$ was used in the absence of additional L3, 19a was obtained with a $22 \%$ isolated yield. An otherwise similar yield was obtained upon treatment of $\mathrm{Ni}(C O D)_{2}$ with L3. At present, we do not have a rationale for the required 1:2.6 ratio of $\mathrm{Ni}: \mathrm{L} 3$ ratio.

[24] Despite considerable synthetic efforts, we were unable to prepare $\mathrm{Ni}(0)(\mathbf{L} 8)$ in analytically pure form.

[25] Although one might argue that allyl chloride intermediates could be generated upon exposure of allyl alcohols to either $\mathrm{MgCl}_{2}$ or $\mathrm{CaCl}_{2}$, control experiments in the absence of $\mathrm{CO}_{2}$ ruled out this possibility. Additionally, we also demonstrate that allyl chlorides are not competent as reaction intermediates en route to either $19 \mathrm{a}$ or $19 \mathrm{~b}$. See ref. 13.

[26] Interestingly, $48 \%$ of $19 \mathrm{~b}$ could be obtained when reacting 18 with $\mathrm{Ni}(\mathrm{COD})_{2} / \mathrm{L} 8$ in the absence of $\mathrm{Zn}, \mathrm{NEt}_{3}$ or $\mathrm{CaCl}_{2}$.

[27] For the in situ generation of $\mathrm{Ni}(\mathrm{I})$ from $\mathrm{Ni}(\mathrm{II})$ : (a) C. A. Laskowski, D. J. Bungum, S. M. Baldwin, S. A. Del Ciello, V. M. lluc, G. L. Hillhouse, J. Am. Chem. Soc. 2013, 135, 18272; (b) J. Breitenfeld, J. Ruiz, M. D. Wodrich, X. Hu, J. Am. Chem. Soc. 2013, 135, 12004; (c) S. Biswas, D. J. Weix, J. Am. Chem. Soc. 2013, 135, 16192; (d) T. Fujihara, K. Nogi, T. Xu, J. Terao, Y. Tsuji J. Am. Chem. Soc. 2012, 134, 9106.

[28] The available experimental data do not allow us to rule out the formation of $\mathrm{Ni}(\mathrm{I})$ intermediates by comproportionation, see for example: (e) J. Cornella, E. Gomez-Bengoa, R. Martin, J. Am. Chem. Soc. 2013, 135,1997; (f) A. Velian, S. Lin, A. J. M. Miller, M. W. Day, T Agapie, J. Am. Chem. Soc. 2010,132, 6296.

[29] Recently, $\mathrm{Ni}(\mathrm{I})$ species have shown to rapidly react with $\mathrm{CO}_{2}: \mathrm{F}$. S. Menges, S. M. Craig, N. Tötsch, A. Bloomfield, S. Ghosh, H.-J. Krüger, M. A. Johnson Angew. Chem., Int. Ed. 2016, 55, 1282; Angew. Chem. 2016, 128, 1304

[30] For a mechanistic hypothesis, see ref. 13

[31] This mechanistic interpretation is somewhat reminiscent of the elegant Pd-catalyzed carboxylation of allenes via $\eta^{1}$-allyl-Pd(II) intermediates possessing otherwise related tridentate pincer-type ligands in which the $\mathrm{CO}_{2}$ insertion occurred at the Y-carbon: (a) H.-W. Suh, L. M. Guard, N Hazari, Chem. Sci. 2014, 5, 3859; (b) J. Takaya, N. Iwasawa, J. Am. Chem. Soc. 2008, 130, 15254.

[32] We cannot rule out that L8 might be redox non-innocent in our carboxylation event. For excellent reviews about redox-active ligands, see: (a) P. Chirik, Angew. Chem. Int. Ed. 2017, DOI: 10.1002/anie.201611959; (b) X. Hu Chem. Sci., 2011, 2, 1867. 


\section{COMMUNICATION}
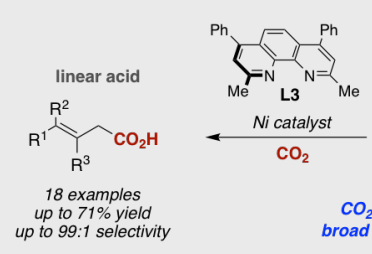

$$
\text { OH }
$$

$\mathrm{CO}_{2}$ acting with dual roles broad scope \& mild conditions

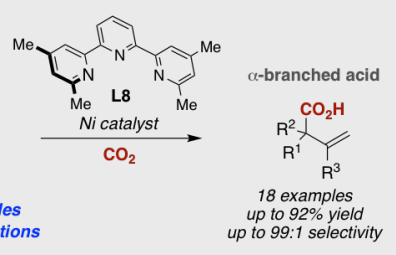

A switchable site-selective Ni-catalyzed carboxylation of allylic alcohols has been developed, in which $\mathrm{CO}_{2}$ is acting with dual roles, both facilitating the a priori uphill $\mathrm{C}-\mathrm{OH}$ cleavage and as a $\mathrm{C} 1$ source This method constitutes the first example of a cross-electrophile coupling of unprotected alcohols in the absence of stoichiometric organometallic species. The protocol is distinguished by a broad scope and an exquisite regiodivergency that can be modulated by the ligand employed.
Manuel van Gemmeren, Marino

Börjesson, Andreu Tortajada, Shang-

Zheng Sun, Keisho Okura and Ruben Martin*

Page No. - Page No.

Title

$\mathrm{Ni}-\mathrm{Catalyzed} \mathrm{switchable} \mathrm{site-selective}$

carboxylation of allyl alcohols with

$\mathrm{CO}_{2}$ 